\title{
E-BUSINESS ADOPTION BY NON-PROFIT CULTURAL INSTITUTIONS
}

\author{
Gabriel Antão ${ }^{1}$ and Pedro Isaías ${ }^{2}$ \\ ${ }^{1}$ Universidade Aberta, Portugal, \\ Rua da Escola Politécnica, 141, 1269-001 Lisboa \\ ${ }^{2}$ The University of Queensland, Australia, \\ Building 17, Level 3, Room 317, The University of Queensland, St Lucia Qld 4072
}

\begin{abstract}
Technological adoption by traditional performing arts institutions is not taken for granted, and being one of the authors a musician in a professional symphony orchestra, many opportunities were perceived where more efficiencies could be achieved through technological adoption, specially regarding e-business. Even though orchestras and other cultural institutions could benefit from e-business adoption, it was not clear why it is not widely implemented by such organizations. In fact, we intended to know how cultural institutions evaluate e-business adoption, why they did (or not) adopt it and how it could benefit them.

From our multiple case study we ca affirm that institutions can fight against the compounded costs through a higher perceived value, both focusing on their artistry and audience development. In fact, e-business enhances the communication with audience, suppliers and clients, while also enabling higher efficiencies and returns. Cultural institutions therefore consider technology, in general, and e-business, in particular, very positive for their performance, and benefiting all stakeholders.
\end{abstract}

\section{KEYWORDS}

e-Business, Cultural Institutions, Cost-Disease, Technology, Audience Development

\section{INTRODUCTION}

The adoption of technology in traditional performing arts institutions is not certain. Institutions such as orchestras are often secular organizations that rely on their long tradition as their best presentation card. Notwithstanding, cultural institutions consider technology, in general, and electronic business, in particular, very positive for their performance, and benefiting all stakeholders: audience, management, artists and (production) offices. The existence of such paradox (benefits are acknowledged, yet not adopted) triggered the need for further investigation. Therefore, we wish to determine to what extent is important for non-profit cultural institutions to implement an e-business model. Hence, this main question should allow us an understanding of the perceived benefits of adopting an e-business model, as well as the emerging difficulties to its adoption.

Engaging in a multiple case study, we aimed to address the issue through open interviews, supported with quantitative data from questionnaires that would make the comparison between organizations more direct. This research is more vertical than horizontal, which might be a flaw from the perspective of generalization. However, this approach enables an analytical generalization instead of a statistical generalization.

We can affirm that institutions can fight against the compounded costs (cost-disease) through a higher perceived value, both focusing on their artistry and audience development, since an enthusiastic audience cannot be ignored. In fact, we understand that electronic business can not only enhance the communication with audience, suppliers and clients, but also enables higher efficiencies and returns. However, the costs inherent to e-business adoption are relevant for such non-profit organizations, which do not generate profit in order to reinvest in the organization. 
In the next sections we will discuss the literature related to the topic (Theoretical Frame) that will help to understand the boundaries of our research, explain our approach to the research topic (Methods of Research), and subsequently we present the Results, followed by a Discussion and Conclusion.

\section{THEORETICAL FRAME}

Hansmann (1981) affirms that the performing arts are mainly - and nowadays - non-profit cultural institutions, in contrast to the paradigm they faced at the beginning of their foundation (especially orchestras), when they could generate income. Among the many different types of cultural institutions, symphony orchestras appear to be the most significant in the western culture (Brodsky, 2006). On the funding level of cultural institutions - and specially on orchestras - there are striking differences among countries, and we can find in the United States a system of low public funding, dependent on patronage/sponsors, and an almost exclusively public funding in Germany, with the highest density of orchestras and theatres (Krebs and Pommerehne, 1995). Hence, the management of institutions across the globe might differ substantially. Cultural institutions have (usually) a factor in common, in that almost the total of their funding is spent in salaries from artists and managers (Walter, 2015), therefore fixed costs, and that these costs might be better spread over a higher number of concerts (Leslie, 2004). We assume that orchestras cannot survive by their selves, and public funding is needed, thus justified by the public service orchestras offer to the communities. However, orchestras should try to have the highest returns out of their activity, so that their efficiencies and returns justify further funds. Some of the possibilities rely on the price discrimination available in the concert venues (Rushton, 2011). Other important costs might include storing, maintaining or replacing materials/parts, which are usually high for both theaters and publishers, and that may have in data banks a future cost-saving solution (Bellini et al., 1999). Orchestras are forced to spare, and also to reduce costs, but this might not lead to greater efficiencies, since in order to maintain or develop artistic quality - and to maintain the best artists, conductors and guests - there is a need for compounded investment (Goldfarb, 1984). Also, orchestras depend on their continuing exchanging surroundings, since they are not closed systems and need a flow of resources form the outside (Heimovics et al., 1993). But we could also consider the arts in a broader market scope, and treat them all as entertainment, considering the arts thus a competitive market (Heilbrun and Gray, 2004). Hence the fact that orchestras are considered, in the first place, as non-profit organizations, they are often compared to large profit-media-arts and other sorts of entertainment, such as sports (Seaman, 2005), making their survival more complicated. Furthermore, orchestras operate in a stable model, often conflicting with the creativity associated with music making, their core activity (Mauskapf, 2012). In fact, orchestras have an above average amount of creative people working within them, but very few creative solutions arise from the organization. In other words, musicians could be asked to participate in the management (corporative management) in order to find new solutions (Starr, 1997). In addition, Bertero (2001) affirms that cultural institutions should not persistently stick to models that have always worked in order to survive (upon a Darwinian model), because they might not be the best solution. Sometimes, it takes a positive (occasionally radical) change to achieve greater benefits and strategic advantages.

When we talk about cost reduction for cultural institutions, we must deal with the concept of cost-disease. First used by Baumol, it describes an economic activity whose costs tend to rise continuously and faster than the economy's rate of inflation (Baumol, 1996), meaning compounding pressures on its economic activity. The author (Baumol, 1967) also believes that there is no enthusiasm or determination that can provide more than a temporary relief, since its consequences are certain in the long run. These pressures are due to the low effect that technology has on productivity and efficiency for non-progressive industries, such as the performing arts and universities. In the other hand, progressive industries might compensate the inflation rate with higher productivity and efficiency rates, therefore reducing costs. Usually, scale and scope economies are possible since orchestral musicians share common knowledge and practice (Malhotra, 1981), and due to the growing level of professionals in the arts sector. In spite of that, the arts do not benefit from the same rates of growing productivity that progressive industries do from technology.

From the audience side, Boiarsky (2003) reveals that the new "Nintendo Generation" has a high visual and kinaesthetic acuity that unconsciously expects more from an "entertaining" performance, leading to symptoms of boredom and low interest for such special performances as from symphony orchestras. 
Performing arts organizations should indeed rethink their approach to technology in order to reach new audiences. In addition, Botstein (1996) considers that we are probably living beyond the golden age of the orchestra and its repertoire, since we are not giving continuity to contemporary life and culture, and more than often just working as a live museum. Nevertheless, there are authors such as Mauskapf (Mauskapf, 2012), who believe that orchestras have never enjoyed a better moment, since music has been made more music and at a higher level than ever, guaranteeing its future. Also, Felton (1994) argues that some reports are exaggerated on their critics over orchestras' deficits, giving a false perception of the real case. Thus, for financial value to be created from the experiences of others, efforts should be made to attract and retain customers, while recruiting new ones (Tschmuck et al., 2013). There are indeed signs of good practices and results, like the audience for opera which is enthusiastic, relatively young and growing in numbers (Botstein, 1994), however, this enthusiasm lies on the inversion of expectations that the audience has concerning the opera role, specially in the way we confront artifice and reality.

Nowadays, orchestras face growing challenges, because in order to focus on artistic quality and on getting the desired stability, they should not seek profits (Boyle, 2007). In fact, they are very unlikely to have any profits at all, since measures focused on the quality are usually non-profitable (Guillard, 1985). However, despite not being profitable-firms, they are often forced to act as such (Olson et al., 2005), striving for more efficiencies and returns, a purpose we believe could be facilitated by the adoption of electronic business.

Electronic business may be defined as undertaking organizational processes as buying, selling, transferring, or exchanging products, services, or information through electronic means as computers and the Internet (Rainer et al., 2014), as part of a greater economic paradigm which brought significant transformations in businesses, namely on the technological level of networks and communications (Matsuo and Colomo-palacios, 2013). We must refer to the benefits of information systems as usually not recognizable in traditional measures as returns on investment, and other financial measures, hence the importance of this investigation to understand the perception of managers beyond financial data. The reaped benefits can be acknowledged through a strategical analysis to the organization, on the efficiency and productivity levels, and eventually in higher financial returns (Isaías and Issa, 2015).

\section{METHODS OF RESEARCH}

We decided to engage in case study research, because it focus on the gathering of data concerning a particular person, social setting, event or group, in order to understand how it operates or works (Berg, 2001). Despite the fact that case study research has been widely criticized, we believe it can be of great value when understanding specific situations, as the one we are studying concerning the e-business in cultural institutions. Hence, the case study must demonstrate its reliability and validity, which is difficult due to the uniqueness of situations (Cohen et al., 2007). Also, the strength of the conclusions from a single case study might not be very high, thus the use of multiple cases can add strength to the conclusions.

In order to study the case, we tried to persuade several institutions to participate, having found three (3) institutions, from two (2) different countries and in two (2) different cultural areas, who wished to contribute under anonymity. In order to gather new data, we decided to apply both open interviews and questionnaires, thus qualitative and quantitative approaches, respectively. As affirmed by Saunders, Lewis and Thornhill (2009), researches often require a combination of primary and secondary data in order to answer the research questions and fulfill the objectives. We indeed pursue our research recurring to mixed methods, thus believing they could provide the most significant data for our research question and objectives.

Concerning the open-ended interviews, they provide a solution that combines structure and flexibility (Legard et al., 2003), enabling us to cover all the important topics in depth and explore eventual new subjects during the interview. In order to analyse the great amount of data obtained, we used the software $n$ Vivo so we could reap greater benefits from our data. The interviews covered important topics, describing the institutions and their activity, their relationship with technology and how it affects their core activity - specifically the adoption of technological tools, its benefits and impact in the daily life of the institution - and the e-business topic, namely if it is known by the institutions and which are the perceived benefits and difficulties of its adoption.

The questionnaires lead to a descriptive research (Saunders et al., 2009) and represent a valuable complement to the interviews. This is particularly important in order to engage in triangulation, which 
includes the use of different approaches, methods or sources to validate conclusions drawn from the data obtained (Richtie and Lewis, 2003). Still concerning the questionnaires, we aim for discrete data, essentially numeric and category data, organized upon Likert scales. The questionnaires covered a detailed description of the organization, a full description of technological adoption and how its impact is perceived by the institution, an extended description of the difficulties to the implementation of e-business, as well as the expected benefits from its use. The questionnaires should be helpful on answering our research objectives - namely the specific benefits and difficulties of adopting an e-business model -, and the open interviews are tailored for deep and rich information, enabling us to understand the impact of e-business in cultural organizations.

\section{RESULTS}

We found that the concept of electronic business is not fully understood by cultural institutions, although importance has been given to technological adoption. Despite the fact that the concept of e-business is not clear yet, these institutions already work with many of its tools on a daily basis. We must say that one (out of the three) institution does fully understand the concept, and has a global strategy in order to implement and reap greater benefits of its use. Most of the institutions consider themselves in a low level of technological adoption, but confirm the adoption and daily use of electronic commerce. They also consider positive the use of technology to automatize processes. In fact, these institutions reveal that online ticket selling is a core activity and that they have ambition of adopting further technological tools and innovations.

Not every institution uses specialized software, but its use has been highlighted as generating several benefits at many levels: management, production offices and audience. We do find a logic between the use of specific software within the institution and its dimension: the use of specific (usually expensive) software only makes sense for bigger organizations. Also, the non-profit and non-progressive character of these institutions makes them less likely to get such advantages as higher productivity and efficiency rates through the use of technology. In addition, the absence of profits makes it harder to (re)invest in such expensive assets as technology. For small cultural organizations, these problems are more evident, since the amount of available resources and expected returns on investment are reduced.

Artistic product (and its quality) is the most important objective for cultural institutions, which might be enhanced by technology. Furthermore, technological developments should only serve the purpose of highlighting the artistic product of the institution. However, the interviewees did not mention any kind of technological benefits in the artistic production itself. Considering Art as communication, it can naturally be enhanced by technology. Henceforth, websites should be knowledge based content platforms, with dynamic contents which motivate to purchase a ticket or simply to generate interest (and discussion) about the institution, its artists and programs. The institutions have special interest in sharing videos online (due to its interactivity) and in social networks. However, they are conscious of the difficulties of getting it to work as they want, since these networks are open spaces, where both compliments and critics are expected. It is clear the need for social networks policies/strategies within the organization, so that its image and values are preserved over the internet mediated platforms. The institutions' website is a key component of their technological activity: electronic commerce is already a daily business for them and a significant share of the tickets being sold online. Henceforth, capabilities as secure page, online payments and information about the programs and the institutions are widely available on their websites. Among the institutions studied, only one had a website optimized for mobile platforms, but other meant to follow this step soon. One institution affirmed their intention of turning their website into a content exhibitor, aiming not only a better communication with the audience, but also extend the life of the products/services, using materials for educational purposes and interactive platforms.

Benefits from technology are unanimous. It enhances productivity and returns, especially for bigger organizations, where the investments in technology are more significant. In general, institutions believe that a higher degree of technological adoption promotes more efficiencies, reduces costs and gives more room for budget planning. They even affirm that technology is crucial for their future, specially concerning possibilities related to social networks and reaching audiences. Not only communication and cost reduction are boasted, also the communication with the client becomes interactive, fast, personalized and - of highest importance - measurable. In addition, in order to fight the effects of the cost-disease, the interviewees cited 
the collaboration between cost-disease affected institutions (cultural institutions and universities) so that chances of both sides can be enhanced.

The institutions recognize their activity as a public service, focused on the artistic quality and on audience development and education, a way of justifying public funding. As a public service, we cannot avoid the topic of price policies. We found that the same programs in smaller cities (venues) offer usually lower prices, when compared to denser populated areas. In addition - and concerning price discrimination - we were noticed that there are limits imposed to the institution (either from the State or City) for minimum and maximum prices, giving less room for price discrimination. Concerning market competitiveness, the Portuguese institutions affirmed to perform within a competitive market, but the third institution - this from a central Europe metropole - mentioned to be in a very competitive market.

There are several limitations to the institution's success: limited budgets (and funding), the almost non-existent rise in productivity, the costly consumer information management, and the adoption of information and communication technologies. Associated with technological adoption is the need for special skills and knowledge. Institutions might offer extra courses to its employees or employ new skilful ones, in order to face the technological challenges. Furthermore, in order to take greater advantage of data, institutions might turn either to external services or recruitment. One of our interviewees makes an interesting statement on this matter: technological adoption does not mean more workload; thus, the number of employees should not rise in order to fulfil the technological requirements. Technology should indeed simplify and clarify processes, and the rich information generated will enable the management to perform better and efficiently. Other difficulties are the projects planned with amateur cultural institutions, because it may represent a step backwards concerning efficiencies on the communication and production levels. When cultural institutions have a certain level of digital adoption, working on less technological-efficient levels (used by amateur institutions) might be frustrating and shows no benefits from the investments in technology. In other words, greater benefits await when everyone adopts technology. The institutions also mention the sponsoring as a way of getting financial flexibility, although this might mean some compulsory programs or image rights usage. Another curious topic, is that the recording market (audio cd's, or video) is not a profitable investment anymore for most cultural institutions, as predicted long ago by Tapscott (2015). However, orchestras and other institutions are forced to have some presence in this market in order to show activity and their level of artistry. We found that instead of investing solely in traditional channels, orchestras might choose modern ways of distribution, such as exclusively digital platforms, in order to avoid greater costs.

\section{DISCUSSION}

The fact that the institutions already use many components of the e-business but do not understand completely the concept, might lead to the conclusion that cultural institutions tend to adopt technological tools separately, and not as a global strategy for the organization. The interviewees did not mention any kind of technological benefits in the artistic production itself, but we believe that the efficiencies obtained on the communication and management level leave more room and time to dedicate to the artistic production. In other words, technological adoption might indirectly serve the artistic production within the organization, as time savings and online document access in order for the artists to prepare themselves, just to mention a daily example. Despite being assumed in the questionnaires that technological adoption had no significant impact on reducing production costs or getting competitive advantages, through the interviews we found evidence that costs in the artistic production were reduced indirectly by technological adoption. Furthermore, if institutions affirm that B2E brings them benefits, then we should strongly consider benefits for employees, namely on arts production. In fact, taking in consideration that the e-business subject was not fully understood by all institutions - and that the interviewees probably never reflected about the topic - some answers might not be consistent with their practices. We believe that triangulation through mixed methods helped to solve this question, and reinforced our choice for this research strategy.

Another question relates to external pressures for technological adoption. In a context of market competition - which might exist, according to our interviewees -, when technological adoption is widely accepted by all the stakeholder, cultural institutions might feel the pressure to follow the trend. However, the opposite might also occur, since adopting edge technology in traditional environments might not lead to more 
efficiencies, because one can only take full advantage of technology if it is adopted by the whole circuit of stakeholders. We usually take the adoption of new technology as a source of competitive advantage, and therefore justifying its acquisition. For cultural institutions, that might not be the case, since most of them have the monopoly over their market, or in other words, their community.

Considering Art as a form of communication, technology can automatically enhance its reach and effectiveness. On the communication level, new streaming possibilities are arising, but we must consider image rights and permissions, which might dissipate apparent cost reduction. Benefits of technological adoption at the communication level seem to be similar to cultural institutions as for other organizations. However, on measuring data and communication, cultural institutions are granted with valuable data and information that can represent one of their unique sources of strategic planning. With detailed data about their audience, institutions are better equipped to improve segmentation and communication.

The institutions mentioned that they try to show their social side, namely sharing backstage work/life from artists, an informal way to communicate, in order to reduce the gap between audience and artists. Social networks open up new possibilities, but require specialized knowledge and policies. However, we might ask about the real purpose of all the new electronic possibilities (like live streaming): might they become a substitute product? We believe that the most striking experience is witnessed in the concert all, and that technology cannot (yet?) capture the whole live experience, but could indeed be an ideal tool to extend the life span of the product (concert), either for advertisement, documenting or educational purposes.

If the performing arts represent a public service, should they consider broadening their focus to children and seniors? We find it logical that in order to get higher returns on their investment, these institutions focus on the segments which can pay the highest price. However, reaching a broader spectrum of the population might better justify their funding or grants. In addition, children should be a particularly important focus, since future audiences should be addressed early on. We can conclude that in denser metropolitan areas, cultural institutions have more room for programming since they have a larger audience, thus the possibility of filing the venues with high quality (less popular programs). The question of financial resources is still important in the metropolitan areas, since popular programs might help to finance quality programming.

Assuming that the institutions make a great amount of online ticket sales, the website as a commercial platform means easiness for the client on purchasing his ticket, but also benefits for the institutions, since valuable data is provided to the institution. Available data for analysis means possibilities of segmentation and price policies and discrimination. Relatively to price policies, we found that the same programs in smaller cities (venues) offer usually lower prices, when comparing to denser populated areas. We believe these differences might lie in the fact that in metropoles, institutions have a larger audience base which could attend the concert, while in smaller areas, institutions might struggle to sell the show completely. Having to follow State/City ticket-price policies, it becomes difficult for the institutions to discriminate prices, losing one of their most valuable tools to generate higher returns. Even if it is understandable that anyone would pay the price correspondent to the real cost of the show, we also agree that a minimum fee should be charged in order to give value to the product/service. However, having similar price policies for both quality and popular programs might reduce the possible financial returns from the organization.

The central Europe institution performs in a very populated area, it probably performs among many other cultural institutions, and eventually some from the same nature. This means that this institution might not only face competition from others of the same nature, as it could face competition from other "entertainment" organizations. Concerning the two Portuguese institutions, we believe that the monopoly situation they have is likely to be maintained, since there is no room for profits, and the limits concerning price policies deny institutions the possibility to reap higher returns from price discrimination.

The partnerships between cost-disease affected organizations was introduced to us as a solution that makes sense within this paradigm. We can find cultural organizations that request studies from universities about their performance or audience rates and development, or even as a mean (help) to implement technological innovation (in the case of technological departments). In the other hand, universities see in cultural institutions an opportunity for their students to make use of their knowledge and expertise in real-life situations. Cultural institutions face new challenges when dealing with the adoption of new technology, since they either must request external services and give additionally formation to its employees, or even employ individuals with knowledge and expertise to deal with the technologies desired. Some frequent errors on this matter concern the misplacement of employers into new technological positions without the skills or expertise required. This might lead to slower rates of work, and eventually the need for external services (help), meaning that technological adoption results in no benefits concerning efficiencies and returns. 
Sponsors are nowadays valuable sources of income for organizations. Notwithstanding, this financial help is usually part of a deal which consists in image selling, direct publicity, or even compulsory programs, which may not fit the objectives of the institution. Therefore, cultural institutions should balance the sponsorship with their artistic objectives in order to keep track of their principal function, the artistic product.

\section{CONCLUSION}

Despite all the mentioned problems concerning the life - and death - of symphony orchestras (and cultural institutions in general), Botstein (1996) believes that they have a brilliant future due to the uniqueness and irreplaceability of its performance and audience. The author compares the (better) situation of symphony orchestras with the Yiddish language which has still to die, but whose death has been announced for over a thousand years. Orchestras can work has a museum of the past and a platform for the modern art/music, and should turn their challenges into opportunities for their advantage.

Concerning our research question, there is an ever-growing importance for e-business implementation in cultural institutions. We understand that electronic business can not only enhance the communication with audience, suppliers and clients, but also enables higher efficiencies and returns, and its impact might be proportional to the size of the institution. Although most cultural institutions have a monopoly over their market, e-business should also be beneficial, since they will not seek for competitive advantages but higher efficiencies and cost reduction. At the communication level, it enables such dynamic institutions to shape their image differently (not rooted in traditional acoustic sound experience), reaching out to new audiences through various channels and multimedia possibilities. In fact, cultural institutions might be able to reshape their image, attain more efficiencies and reach broader audiences, always giving that funds for e-business adoption are within their budget, or when expected cost reduction and higher efficiencies justify and pay off the investment made. The new technological developments set new challenges to cultural institutions but equally as many opportunities. One of the most important lessons from our research is resembled in the words of Douglas Dempster (in Mauskapf, 2012), that institutions affected by the cost-disease should not seek growth through greater productivity but through perceived value. Only controlling the latter, institutions are able to keep pace with the inflationary costs of the economy (Douglas Dempster in Mauskapf, 2012). In order to control such measures as value, institutions must engage with their communities, broaden their audience base, and engage in new technological platforms and practices, namely in educational activities. Also, institutions should seek efficient processes and higher returns despite being usually in a monopoly position in their markets. In fact, due to the ticket price limitations imposed by state or municipality, institutions can hardly engage in price discrimination strategies, but should instead turn their selves to segmentation, which is enhanced by e-business adoption, namely on the data acquired through digital platforms. Cultural institutions consider technology, in general, and electronic business, in particular, very positive for their performance, and benefiting all the stakeholders: audience, management, artists and (production) offices.

\section{REFERENCES}

Baumol, W.J., 1996. Symphony Orchestra Economic: The Fundamental Challenge. Harmony Forum Symphony Orchestras. Inst. 2, 52-54.

Baumol, W.J., 1967. Performing Arts, The Permanent Crisis. Economic Analysis indicates possible extinction. Business Horizon. 10, 47-50.

Bellini, P., Fioravanti, F., Nesi, P., 1999. Managing Music in Orchestras. IEEE Press 32, $26-34$. https://doi.org/10.1109/2.789748

Berg, B., 2001. Qualitative Reserach Methods for the Social Sciences, 4th ed. Allyn and Bacon, Boston, USA.

Bertero, C.O., 2001. Orquestras Sinfônicas: uma metáfora revisitada. Revista Administração de Empresas. 41, 84-88.

Boiarsky, C., 2003. This Is Not Our Fathers' Generation: Web Pages, the Chicago Lyric Opera, and the Philadelphia Orchestra. Journal of Popular Culture. 36, 14-24.

Botstein, L., 1996. The Future of the Orchestra. Music Quarterly, 80, 189-193.

Botstein, L., 1994. The Opera Revival. Music Quarterly, 78, 1-8. 
Boyle, S., 2007. Single serve or package deal? A study of regular attendees to symphony orchestra concerts. International Journal of Nonprofit and Voluntary Sector Marketing. 12, 127-134. https://doi.org/10.1002/nvsm

Brodsky, W., 2006. In the wings of British orchestras: A multi-episode interview study among symphony players. Journal of Occupational and Organizational Psychology. Br. Psychol. Soc. 79, 673-690. https://doi.org/10.1348/096317905X68213

Cohen, L., Manion, L., Morrison, K., 2007. Research methods in education, 6th Edition. ed. Routledge, New York, USA. https://doi.org/10.1080/19415257.2011.643130

Felton, M.V., 1994. Evidence of the existence of the cost disease in the performing arts. Journal of Cultural Economics. 18, 301-312. https://doi.org/10.1007/BF01079761

Goldfarb, R.S., 1984. A Davis-Bacon Musicale: Symphony Orchestras as Migrant Labor. Journal of Labor Research. $\mathrm{V}, 427-433$.

Guillard, J.-P., 1985. The Symphony as a Public Service: The Orchestra of Paris. Journal of Cultural Economics. 9, $35-47$.

Gustafsson, J., 2017. Single case studies vs. multiple case studies: A comparative study. Halmstad, Sweden.

Hansmann, H., 1981. Nonprofit Enterprise in the Performing Arts. Bell Journal of Economics. 12, 341-361. https://doi.org/10.2307/3003560

Heilbrun, J., Gray, C.M., 2004. The Economics of Art and Culture, 2nd ed. Cambridge University Press, New York, USA. https://doi.org/10.1017/CBO9781107415324.004

Heimovics, R.D., Herman, R.D., Coughlin, C.L.J., 1993. Executive Leadership and Resource Dependence in Nonprofit Organizations: A Frame Analysis. Public Adm. Rev. 53, 419-427.

Isaías, P., Issa, T., 2015. high Level Models and Methodologies for Information Systems. Springer-Verlag, New York, USA.

Krebs, S., Pommerehne, W.W., 1995. Politico-economic interactions of German public performing arts institutions. Journal of Cultural Economics 19, 17-32. https://doi.org/10.1007/BF01074430

Legard, R., Keegan, J., Ward, K., 2003. In-Depth Interviews, in: Qualitative Research Practice - A Guide for Social Science Students and Researchers. Sage Publications, London, UK, pp. 138-169.

Leslie, P., 2004. Price discrimination in Broadway theater. RAND Journal of Economics. 35, 520-541.

Malhotra, V.A., 1981. The social accomplishment of music in a symphony orchestra: A phenomenological analysis. Qualitative Sociology 4, 102-125. https://doi.org/10.1007/BF00987214

Matsuo, T., Colomo-palacios, R., 2013. Electronic Business and Marketing: New Trends on Its Process and Applications. Springer.

Mauskapf, M.G., 2012. Enduring Crisis, Ensuring Survival: Artistry, Economics, and the American Symphony Orchestra. The University of Michigan.

Olson, J.R., Belohlav, J.A., Boyer, K.K., 2005. Operational, economic and mission elements in not-for-profit organizations: The case of the Chicago Symphony Orchestra. Journal Opera Management. 23, 125-142. https://doi.org/10.1016/j.jom.2004.07.008

Rainer, R.K., Prince, B., Cegielski, C., 2014. Introduction to Information Systems: Supporting and Transforming Business, 5th Editio. ed. Wiley, New York, USA.

Richtie, J., Lewis, J., 2003. Qualitative Research Practice: A Guide for Social Science Students and Researchers. Sage Publications, London, UK.

Rushton, M., 2011. Pricing the Arts, in: Towse, R. (Ed.), A Handbook of Cultural Economics. Edward Elgar, Cheltenham, UK, pp. 350-355.

Saunders, M., Lewis, P., Thornhill, A., 2009. Research Methods for Business Students, 5th ed. Prentice Hall Financial Times, Essex, Uk.

Seaman, B.A., 2005. Attendance and Public Participation in the Performing Arts: A Review of the Empirical Literature (No. 06-25). https://doi.org/10.2139/ssrn.895099

Starr, S.F., 1997. Symphony Orchestras: How Did We Get Here? Where Are We Going? Harmony Forum Symphony Orchestras. Inst. 5, 73-88.

Tapscott, D., 2015. The Digital Economy Anniversary Edition: Rethinking Promise and Peril in the Age of Networked Intelligence, 2nd ed. McGraw-Hll Professional, USA.

Tschmuck, P., Pearce, P.L., Campbell, S., 2013. Music Business and the Experience Economy: The Australian Case. Springer-Verlag, Berlin-Heidelberg.

Walter, C., 2015. Arts Management: An Entrepreneurial Approach. Routledge, New York, USA. https://doi.org/10.1017/CBO9781107415324.004 